\title{
Produções materiais e culturais fora da expectativa do "padrão etário": tendências de mercado e pressões sociais que influenciam os consumidores adultos de livros ilustrados
}

Material and cultural productions out of the "age appropriate": market trends and the influence of social pressure in adult consumers of illustration books

\author{
SADDY, Bruna Spinola; Mestre em Design; Pontifícia Universidade Católica do Rio de Janeiro \\ brunasaddy@gmail.com \\ FARBIARZ, Jackeline Lima; Doutora em Educação; Pontifícia Universidade Católica do Rio de Janeiro \\ jackeline@puc-rio.br \\ CARVALHO, Ricardo Artur Pereira de; Doutor em Design; Escola Superior de Desenho Industrial da \\ Universidade do Estado do Rio de Janeiro \\ rickartur@gmail.com
}

\section{Resumo}

Este artigo expõe o resultado de uma pesquisa de revisão bibliográfica narrativa realizada com o objetivo de conhecer, descrever e refletir sobre como a relação entre consumidores adultos e produtos ditos "infantis", especialmente no tocante a livros ilustrados, é influenciada por fatores sociais. São levantadas algumas tendências e movimentos de mercado que demonstram experimentações e o consumo de tais produções por adultos. São, também, discutidas pressões sociais que constrangem o indivíduo a adotar certas posturas e a consumir certos produtos culturais para seguir aquilo que é considerado de "bom gosto" (BOURDIEU, 1998) e perceber diversas visões do que seria considerado arte (RANCIÈRE, 2009), de quem pode consumi-la e quais são as hierarquias entre elas.

Palavras Chave: design; editorial; consumo.

\begin{abstract}
This document presents the result of a narrative literature review made with the objective of researching, describing and reflecting upon the relation between adult consumers and products usually associated with children, especially illustrated books, and how this relation is influenced by social factors. Some market trends and movements are highlighted in order to demonstrate actual experiences of adult consumption of such products. It is presented a discussion about social pressures that may constrain an individual to adopt certain postures and consumption habits that abides what is regarded as "good taste" (BOURDIEU, 1998) and the visions of what is regarded as art (RANCIÈRE, 2009), which persons may consume it and it's hierarchy.
\end{abstract}

Keywords: design; editorial; consumption. 


\section{Introdução}

Este artigo expõe o resultado de uma pesquisa de revisão bibliográfica narrativa realizada com o objetivo de conhecer, descrever e refletir sobre o consumo, por adultos, de bens culturais e materiais considerados pelo senso comum como infantis, especialmente focando na questão do livro ilustrado de ficção em prosa, e de como a relação entre consumidores adultos e produtos ditos "infantis" é influenciada por fatores sociais. É discutido que existem diversas pressões sociais que constrangem o indivíduo a adotar certas posturas e a consumir certos produtos culturais para seguir aquilo que é considerado de "bom gosto" e que existem diversas visões do que seria considerado arte, de quem pode consumi-la e quais são as hierarquias entre elas.

Para a fundamentação teórica principal do trabalho, são levantados para a discussão os conceitos de diversos autores como Bourdieu (1998) e Rancière (2009). O presente artigo é parte da pesquisa de dissertação de mestrado "Entendeu ou quer que eu desenhe? Um estudo sobre a percepção dos leitores sobre os livros ilustrados de ficção em prosa dirigidos ao público adulto" (SADDY, 2016).

A relevância desta pesquisa se encontra numa possível contribuição para o incentivo à leitura de um grande público consumidor em potencial. Também, ao se procurar por artigos, teses e dissertações sobre o tema, vê-se que há uma abundante pesquisa sobre a ilustração em livros infanto-juvenis, enquanto a ilustração dirigida para o público adulto é pouco abordada. Acredita-se que há uma relevância para o campo em levantar a discussão sobre a importância da percepção da ilustração como participante da significação no ato da leitura, por parte de qualquer público leitor, com potência para contribuir na formação visual dos indivíduos.

É importante salientar que não é o objetivo dos autores rivalizar ou hierarquizar as linguagens verbal e visual, tampouco propor que todos os livros dirigidos a um público ou outro deveriam ter, ou não, imagens. Pelo contrário, entende-se aqui que o público consumidor é diverso e complexo e que, portanto, há espaço e demanda para a produção e fruição de itens e obras que experimentem e ousem em linguagens e questionamentos de padrões de comportamento.

\section{Consumidores que "colorem fora das linhas": o entendimento do consumo "adequado" para adultos}

Nossa vida cotidiana está inundada de imagens e ilustrações nos mais diversos textos, contextos e tecnologias. Em outdoors, revistas, placas, sinais, na televisão e nas redes sociais, as imagens não só acompanham o texto, mas muitas vezes, são o "texto" principal, comunicando, seduzindo e chamando a atenção do leitor. Nunca se produziu ou se consumiu tantas imagens na história da humanidade e cada vez mais pessoas têm acesso a elas, especialmente pelos meios digitais. No entanto, essa situação de grande oferta de imagens, e de suas possibilidades de comunicação e de fruição, parece encontrar barreiras em alguns suportes, como é o caso do livro de ficção em prosa dirigido ao público adulto ${ }^{1}$.

\footnotetext{
1 No artigo “Uma pesquisa de campo sobre a incidência de ilustrações nos livros dirigidos ao público adulto" (SADDY,FARBIARZ, 2014), também produzido durante a pesquisa de mestrado da primeira autora, em uma grande livraria do Rio de Janeiro foram analisados 233 livros de ficção e, destes, somente 9 (6,3\%) eram livros ilustrados de ficção não dirigidos especificamente para o público infanto-juvenil (segundo gênero literário dado pela editora e
} 
O contexto social é um dos aspectos da vida que pode ter grande influência sobre a pessoa. Perscrutando atentamente a vida em sociedade, pode-se ver que um indivíduo tem diversos pensamentos, atitudes e até mesmo gostos (que se considerariam) pessoais fortemente influenciados pelo grupo. Há uma série de construções sociais - pressões, expectativas, paradigmas, tradições etc. - que ditam o que é considerado "adequado", esperado, para cada sexo, classe socioeconômica, faixa etária, etc. As possíveis consequências desses constrangimentos podem ser, por exemplo, desde qual tipo de comportamento é esperado de um indivíduo do sexo masculino na sociedade brasileira atual, até a que tipo de linguagem é considerada adequada para a comunicação e experiência estética de cada faixa etária.

Assim como diversas outras facetas da identidade de um indivíduo, a construção social do "ser adulto" ou "ser criança" é um produto de um contexto cultural e histórico. Por muitos séculos, o entendimento da infância como uma fase especial da vida simplesmente não existiu, muito menos a separação de produtos culturais específicos para esta ou aquela idade (FORTY, 2007, p. 101). No entanto, é notável que em nossa sociedade atual esta percepção de divisão da vida em fases cronológicas com características e necessidades específicas (e, deste modo, produtos específicos) faz parte do senso comum e é, também, estudada e reforçada por diversas áreas do saber, como por exemplo a medicina, o direito e a psicologia.

O ramo da medicina que atende ao cuidado especial de crianças e adolescentes é a pediatria. Pessoas até 13 anos são atendidas por esta especialização e, após esta idade, podem ser acompanhadas por um clínico geral, pois seus corpos já são como os de um adulto. Na lei brasileira, a maioridade penal, isto é, a idade a partir da qual o indivíduo responde integralmente à Justiça, sem qualquer tipo de concessão diferenciada para crianças, é 18 anos. A Constituição Brasileira entende que, a partir de então, a pessoa tem consciência das consequências dos seus atos, portanto, e responde como um adulto.

Já no ramo da psicologia, não existe uma definição etária tão precisa. Entre algumas ideias em debate, está a teoria do desenvolvimento psicossocial de Erik Erikson (1998) que sugere que o período de vida que define o jovem adulto - etapa da vida diferenciada do adulto - vai até aos 40 anos. Outro estudo (ARNETT, 1997) considera que, para além da faixa de idade, é mais relevante a percepção dos próprios jovens adultos pesquisados (de 18 a 29 anos) do que é ser um adulto. As respostas a tais questionamentos atestam que esta noção estaria mais relacionada a certas posturas individuais, tais como "aceitar a responsabilidade dos seus atos", "decidir suas próprias crenças e valores morais" e "estabelecer uma relação de igualdade com os próprios pais, sendo percebido por eles como um igual" do que com ações que tradicionalmente são consideradas próprias do mundo adulto e, até mesmo, consideradas etapas de transição, ritos de passagem modernos, para o mesmo, como trabalhar, casar e ter filhos. Esta mesma pesquisa sugere que a percepção constatada é que "a transição para a vida adulta se dá em termos intangíveis, graduais, psicológicos e individuais" (1997, p.3).

No entanto, frases corriqueiras como "isto é coisa de criança" ou "estou muito velho pra isso" mostram pequenos, mas reveladores índices do que é considerado adequado para o consumo de adultos e mostram que, no senso comum, estas separações e categorizações vão muito além de aspectos fisiológicos, legais e de posicionamentos, abrangendo por vezes questões de gosto e,

livraria), revelando uma baixa oferta de livros de ficção ilustrados dirigidos ao público adulto. 
portanto, de consumo.

Conheço um adulto que coleciona quebra-cabeças. Seu hobby é montar puzzles e o desafio é que sejam cada vez maiores, com muitas mil peças. Na última Copa do Mundo, ele foi um dos torcedores mais empenhados em completar o álbum de figurinhas das seleções. Frequentava pontos de troca e montou um grupo na Internet. Suas camisetas de lazer tem estampado o escudo do Batman, do Super-Homem ou de algum outro personagem de HQ. (...) É importante esclarecer que não são apenas os rapazes que se transformam em adultos infantilizados. Quantas são as meninas que viram mulheres, mas não se desfazem dos seus bichos de pelúcia?" (BARBOSA, 2016, p. 73)

Como pode ser visto no trecho acima, por vezes, ter hábitos de consumo material e cultural de produtos que são corriqueiramente associados ao universo infantil é visto como pouco usual ou até mesmo degradante, no sentido de que a maturidade psicológica da pessoa e sua capacidade de ser um adulto "funcional" é diretamente e proporcionalmente relacionada aos produtos.

\section{O gosto "pessoal" e as pressões sociais}

Voltando-nos especificamente para a questão das Artes, segundo Rancière (2009), há uma dimensão política nas Artes e na Cultura denominada Partilha do Sensível, que é, ao mesmo tempo, a maneira pela qual todas as pessoas experimentam e compreendem a Arte como um conjunto comum e, também, como essa participação é dividida entre grupos menores, que podem ou não ser socialmente aceitos como produtores ou apreciadores destas artes. Em outras palavras, a partilha do sensível é a cultura que nos enreda, nos contextualiza e nos define como um grupo coeso, ao mesmo tempo em que a divide em "quinhões" de diferentes fruições possíveis. Esta divisão é profundamente política porque, nas palavras do filósofo: "ocupa-se do que se vê e do que se pode dizer sobre o que é visto, de quem tem competência para ver e qualidade para dizer, das propriedades do espaço e dos possíveis do tempo" (RANCIÈRE, 2009, p.16-17).

Em um sentido similar, Bourdieu (1998), com seus estudos sobre o "bom gosto", mostra que aquilo que seria considerado uma predileção pessoal, em relação aos produtos culturais, é fortemente influenciado pelas pressões e predisposições do contexto social. Em outras palavras, uma pessoa que não é encorajada pelo seu contexto social e por suas experiências pessoais anteriores a ter contato com determinado produto cultural dificilmente adquirirá um "gosto" por ele. Essa suposta predileção natural, intrínseca ou pessoal é, na verdade, formada pelo habitus, que é um conjunto de situações, ações e percepções que cada sujeito vai adquirindo ao longo de sua vida e que vai além dele mesmo, simultaneamente, sendo formado pelas estruturas relacionais nas quais ele se insere (SOCHA, 2008). Essas dimensões pessoais e conjecturais podem ser tanto capitais econômicos (como renda, salário, posses materiais), quanto culturais (tais como posse de bens didáticos ou artísticos e formação acadêmica). Embora os estudos do filósofo francês se foquem no estudo distinções dos gostos como ferramenta de dominação cultural, o presente trabalho apropria-se deste conceito para a reflexão sobre o "adequado".

É muito importante, porém, salientar que, embora tanto o conceito de partilha do sensível, de Rancière, quanto o habitus, de Bourdieu corroborem a ideia de que uma pessoa é influenciada pelo todo, que por sua vez é formado por diversos indivíduos que reconstroem e perpetuam as ideias que os influenciam, os pensadores divergem sobre um ponto crucial na compreensão do que 
é a Arte e como ela opera no sujeito. Enquanto Bourdieu acredita que muitas vezes a Arte é usada como ferramenta de dominação e diferenciação pela elite e que, para que um sujeito possa fruir uma obra ele necessariamente precisa de uma experiência, um background, (formada também pelo habitus) que propicie e reforce essa apreciação, caso contrário se sentirá rejeitado e a rejeitará; para Rancière a Arte justamente deve provocar deslocamentos, podendo desta maneira propiciar a este indivíduo novas visões de mundo, insights, epifanias, e fazer o sujeito repensar sua própria realidade a partir de um outro ponto de vista.

Devido a esta divisão entre consumos e produções "adequadas", reforçada pelos dois autores, apesar de suas diferenças, chegam à vida cotidiana pensamentos do juízo comum que podem reforçar o afastamento entre os sujeitos adultos e os livros de ficção ilustrados. Existe uma pressão e uma tradição de limitação quanto à fruição e à produção visual, que cresce durante o desenvolvimento do sujeito, (LACERDA; FARBIARZ, 2013) que podem levar a um afastamento da produção e consumo de imagens em certos meios e ocasiões.

Uma demonstração desse recorte político é o discurso construído por Platão e que, mais tarde, inspira Rancière (2009) como base para um regime de identificação das artes. Nesse discurso, não só as imagens, os simulacros, seriam sombras das sombras, segundo o raciocínio da Alegoria da Caverna, como servem, no discurso Fedro (SÓCRATES, 2012), para traçar uma comparação e demonstrar os defeitos e os perigos da palavra escrita:

O uso da escrita, Fedro, tem um inconveniente que se assemelha à pintura. Também as figuras pintadas têm a atitude de pessoas vivas, mas se alguém as interrogar conserva-seão gravemente caladas. O mesmo sucede com os discursos. Falam das cousas como se as conhecessem, mas quando alguém quer informar-se sobre qualquer ponto do assunto exposto, eles se limitam a repetir sempre a mesma coisa. Uma vez escrito, um discurso sai a vagar por toda a parte, não só entre os conhecedores, mas também entre os que não o entendem, e nunca se pode dizer para quem serve e para quem não serve." (2012, p.37)

Para Sócrates havia apenas uma única interpretação correta para um texto, e ela só poderia ser transmitida por meio oral, por pessoas treinadas no âmbito intelectual e para indivíduos específicos. Como afirma Fischer (2006, p. 48), "Sócrates exigia do texto o caráter unidimensional da oralidade." É interessante para os leitores deste artigo observar que, ao criticar a palavra escrita, o filósofo grego a compara com a pintura de modo depreciativo.

De Rancière também trazemos para nossa discussão os conceitos de Regimes de Identificação da Arte, que são diferentes maneiras de se compreender o que é a Arte, como ela é feita e quais os seus propósitos. Em muito breves linhas, o regime ético diferencia as maneiras de fazer entre os simulacros - que apenas imitam a aparência das coisas e não tem um fim de aprendizado -, e as artes verdadeiras - saberes fundados na imitação de um modelo, mas com um fim próprio de educação e cidadania. O regime poético estabelece formas de normatividade para as artes, definindo, por exemplo, gêneros e hierarquias de artes. Por fim, o regime estético abole todas as regras e reconhece a arte como uma só (RANCIÈRE, 2009, p.28-34).

É importante compreender que os três regimes propostos existem simultaneamente no tempo e até mesmo nos próprios indivíduos. É possível, por exemplo, que uma mesma pessoa acredite que "tudo pode ser arte", uma visão mais ligada ao regime estético, e que a cultura da palavra escrita é superior - culturalmente, intelectualmente, criativamente etc. - a das imagens, uma visão mais ligada ao regime poético.

A visão de uma constatada separação de públicos, no caso específico do livro de ficção 
ilustrado, segundo adequação etária, é verificada pelas educadoras e autoras Maria Nikolajeva e Carole Scott (2011), que consideram que existe um "preconceito comum de que os livros ilustrados são literatura para crianças muito novas" (2011, p.330). De acordo com as autoras, a imagem que, nos livros ilustrados, é "senão dominante, evidente" está associada, na teoria psicológica de Lacan, à fase imaginária, de imagem, de comunicação pré-verbal do desenvolvimento do indivíduo e ligada ao feminino, à "mãe". Para passar à fase simbólica, dos signos convencionados, ordenados, ligados ao masculino, ao "pai", a criança deve "rejeitar a mãe". No entanto, existe uma terceira fase, a "real" que é "uma tentativa - segundo Lacan, frequentemente fracassada - de reconciliar as duas anteriores." Segundo elas, o livro ilustrado - como nenhuma outra forma literária - pode agir neste sentido, sendo uma ponte que "transpõem o abismo entre o verbal e o não-verbal" para públicos variados (LACAN apud Nikolajeva; SCOTT, 2011, p.330).

Se questões relativas à valoração e hierarquização entre conteúdo verbal/conteúdo visual sustentam o paradigma de ausência de ilustrações no livro de ficção em prosa dirigido ao público adulto em decorrência das pressões e expectativas culturais sofridas pelos leitores, é possível inferir que estando em um contexto no qual o padrão, reforçado por diversas frentes, é o de que uma obra literária para adultos tradicionalmente não conta com ilustrações, o consumidor pode ter uma reação de estranhamento a um livro que não supra esta expectativa. Ou, até mesmo os produtores de livros, por esta mesma tradição, nem cheguem a considerar a possibilidade de incluir esta forma de linguagem numa obra dirigida para adultos.

\section{Divergente: Tendências de consumo fora do "esperado"}

O título deste item é uma brincadeira com o título de um livro de mesmo nome, voltado para jovens (segundo o site da Livraria Cultura, ele está na categoria "teen - Literatura - Ficção científica"), mas que foi um grande sucesso entre públicos de variadas faixas etárias. Esta obra e outras como a série Harry Potter, Crepúsculo, A Culpa é das Estrelas e Jogos Vorazes, fazem parte de um gênero de literatura chamado Young Adult Fiction, ou simplesmente YA, em português Ficção para Jovens Adultos.

Como o nome do gênero transparece, o seu público-alvo são jovens adultos e adolescentes. Embora algumas instituições marquem uma certa equivalência ao público dos livros juvenis, ou seja crianças de 14 aos 18 anos de idade, outras fontes, como a teoria do desenvolvimento psicossocial de Erik Erikson (1998), brevemente discutida anteriormente, sugerem que o período de vida que define o jovem adulto vai até os 40 anos. Independente da precisão da faixa etária, o surgimento e sucesso deste tipo de obra sugere a existência de interesse de parte da população legalmente adulta por temas tradicionalmente associados com o público infantil. Na verdade, existem até mesmo edições especiais "adultas" (adult edition) de certos livros YA ou infanto-juvenis com o mesmo conteúdo textual da obra original, mas com capas mais "sóbrias", revelando um possível constrangimento por parte do próprio consumidor adulto de ser visto publicamente fruindo uma obra "de criança" (ver figuras de 1 a 10, que mostram títulos exemplares por sua alta popularidade). 
Figuras 1 a 6 - À esquerda, veem-se as capa "tradicionais" dos livros A Bússula Dourada, Divergente e Coraline; à direita veem-se as suas versões adult edition.
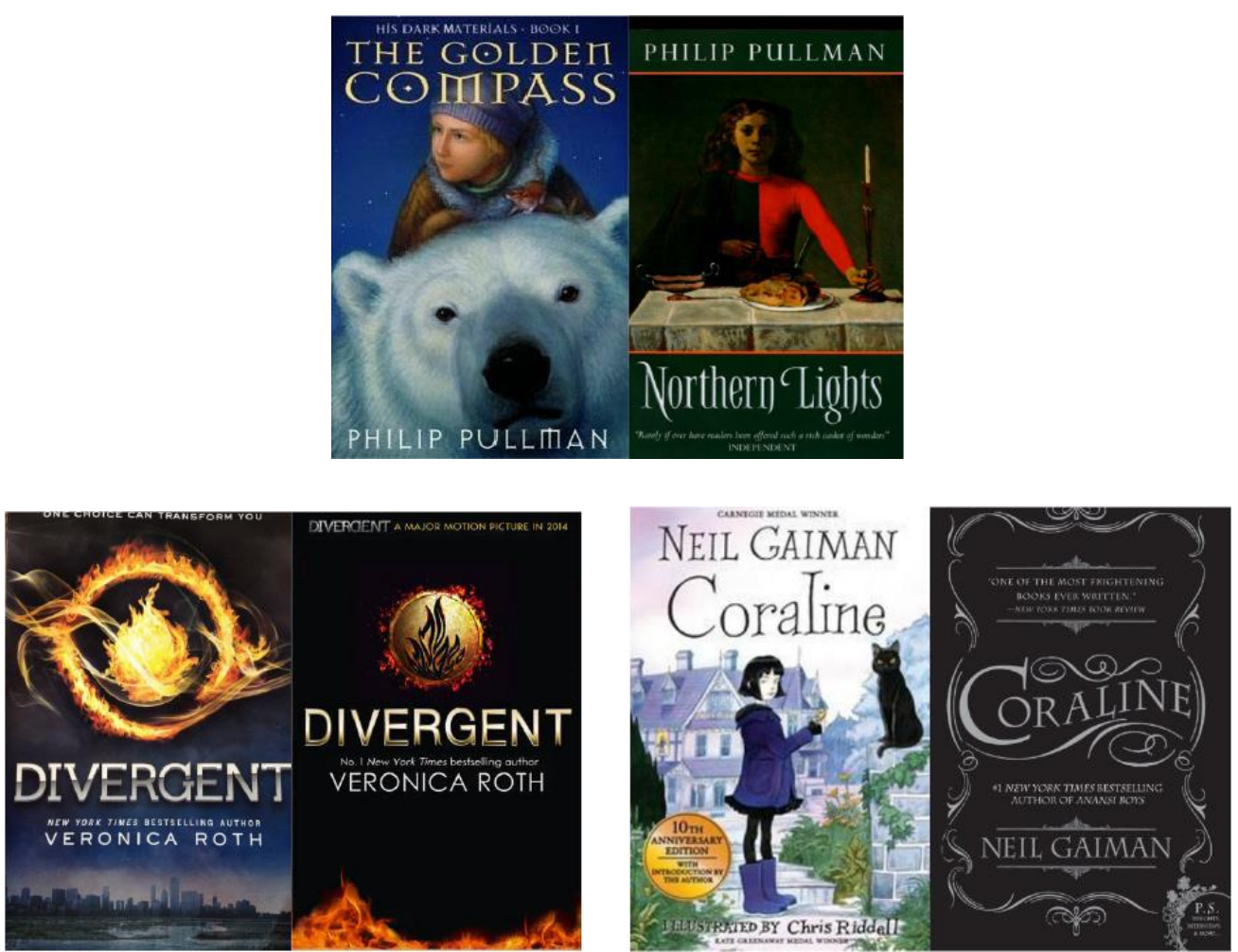

Fontes: Editoras Yearling, Scholastic, Epic Reads, Harpercollins, Bloomsbury e Harper Perennial.

Figuras 7 a 10: À esquerda acima, vêem-se as capa "tradicionais" dos livros da série Harry Potter; as demais figuras mostram diferentes coleções adult edition.
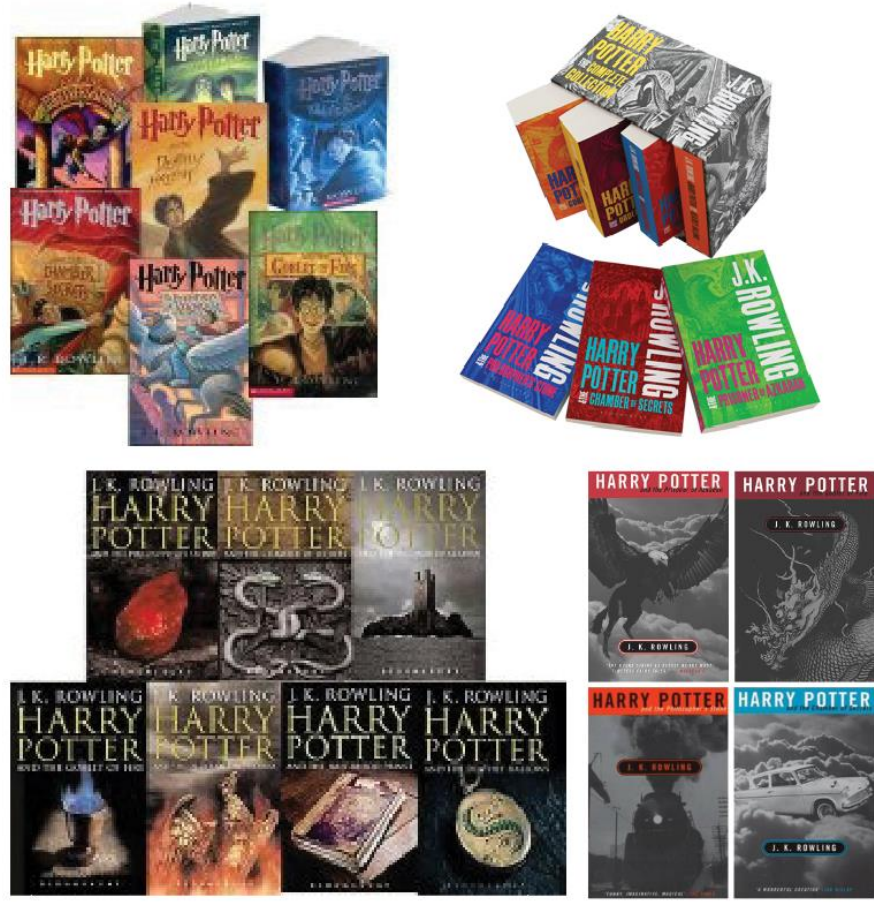

Fontes: Editoras Scholastic e Bloomsbury. 
Outros possíveis exemplos editoriais contemporâneos de transgressões e experimentos de deslocamentos de linguagens e públicos são: um livro infantil sem ilustrações e os livros de colorir para adultos. Estes são de especial interesse para a pesquisa pela questão da ilustração.

O livro infantil em questão é O livro sem figuras (ver figura 11), que como diz o título não tem absolutamente nenhuma ilustração, o que é extremamente incomum para um livro atual dirigido a crianças. Com muito foco na expressão tipográfica e principalmente no humor, este livro foi feito para a leitura em voz alta, por um adulto, para uma criança. $O$ texto sugere que a pessoa que está lendo-o (presumivelmente o adulto que lê para a criança) é "obrigada" a ler tudo aquilo que está escrito no livro em voz alta e foi um grande sucesso de vendas, permanecendo por muitas semanas nos primeiros lugares da lista de mais vendidos do New York Times.

Figura 11: Capa do O livro sem figuras.

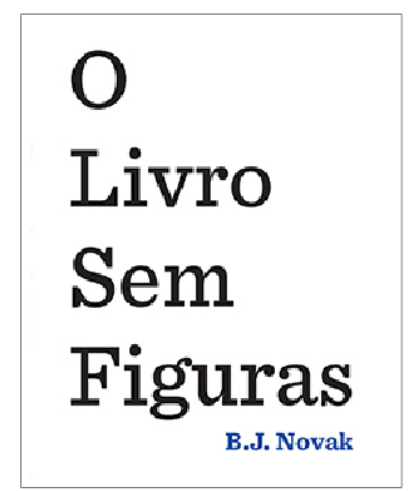

Fonte: Editora Intrínseca.

Já os livros de colorir para adultos foram um breve e recente fenômeno editorial, alcançando os primeiros lugares das listas de mais vendidos brasileiras ${ }^{2}$ e sendo calorosamente discutidos pelos críticos e pelo público, que questionam tanto a sua validade como um livro, quanto sua destinação para o público adulto. Tais estranhamentos e, até mesmo, preconceitos são bem gritantes como deixa transparecer o título "Barbies com lombadas" (AUGUSTO, 2015) de um artigo do jornal Estadão, no qual o autor chama de "infantilizadas e desocupadas" (com o gênero propositalmente no feminino) os consumidores de tais obras. Já a Folha de São Paulo e a Veja nem consideram tais obras como livros ${ }^{3}$ e, dessa maneira não entraram nas suas respectivas contagens dos mais vendidos. Um editor-executivo de uma importante editora brasileira propôs uma "campanha pela maioridade intelectual" contra o que ele chama de "triunfo da não-leitura"4. Por outro lado, há uma defesa dessas obras como relaxantes, terapêuticas e como uma forma de resgate do lúdico e da arte na vida adulta, como ilustra o texto do site de opinião Revista Bula:

2 PUBISHING NEWS. Mais vendidos. 2015, jun. Disponível em: <http://publishnews.com.br/telas/maisvendidos/ranking-mensal.aspx> Acesso em: 28 de jun de 2015.

${ }^{3}$ BALLOUSSIER, A. V. Livros de colorir levam amor e ódio ao mercado editorial. Folha de S. Paulo. São Paulo: 2015. Mai. Disponível em: <https://www1.folha.uol.com.br/ilustrada/2015/05/1633554-livros-de-colorir-levam-amor-e-odio-aomercado-editorial.shtml> Acesso em: 13 de jul 2015.

${ }^{4}$ FORTUNA, M. 'Com os livros de colorir, vivemos o triunfo total da não-leitura', dispara editor. O Globo. Rio de Janeiro: 2015. Jun. Disponível em: <http://blogs.oglobo.globo.com/gente-boa/post/com-os-livros-de-colorir-vivemos-o-triunfototal-da-nao-leitura-dispara-editor.html> Acesso em: 13 de jul 2015. 
A arte e o esporte são tratados nos bancos escolares meramente como matérias de segundo plano, do último degrau da escada hierárquica das disciplinas. (...) Neste momento, as artes e a espiritualidade assumem um papel essencial como subterfúgio ou conforto para preencher este vazio: suprimir o lúdico que nos foi extraído na infância, assim, transportamo-las de volta ao nosso cotidiano adulto, já carente de criatividade. (Ramos, 2015)

Ambos os exemplos levantam perguntas e possibilidades, além de gerar reações, muitas vezes extremas, ao mesmo tempo que mostram como essa discussão de linguagens e faixa etária é extremamente relevante e rica para o mercado editorial e para a leitura.

Figura 12: Internautas discutem os livros de colorir para adultos no post sobre o artigo do The Guardian: "livros de colorir para adultos soa errado" diz um, logo seguido por uma segunda pessoa que diz "eu amo meus livros de colorir"

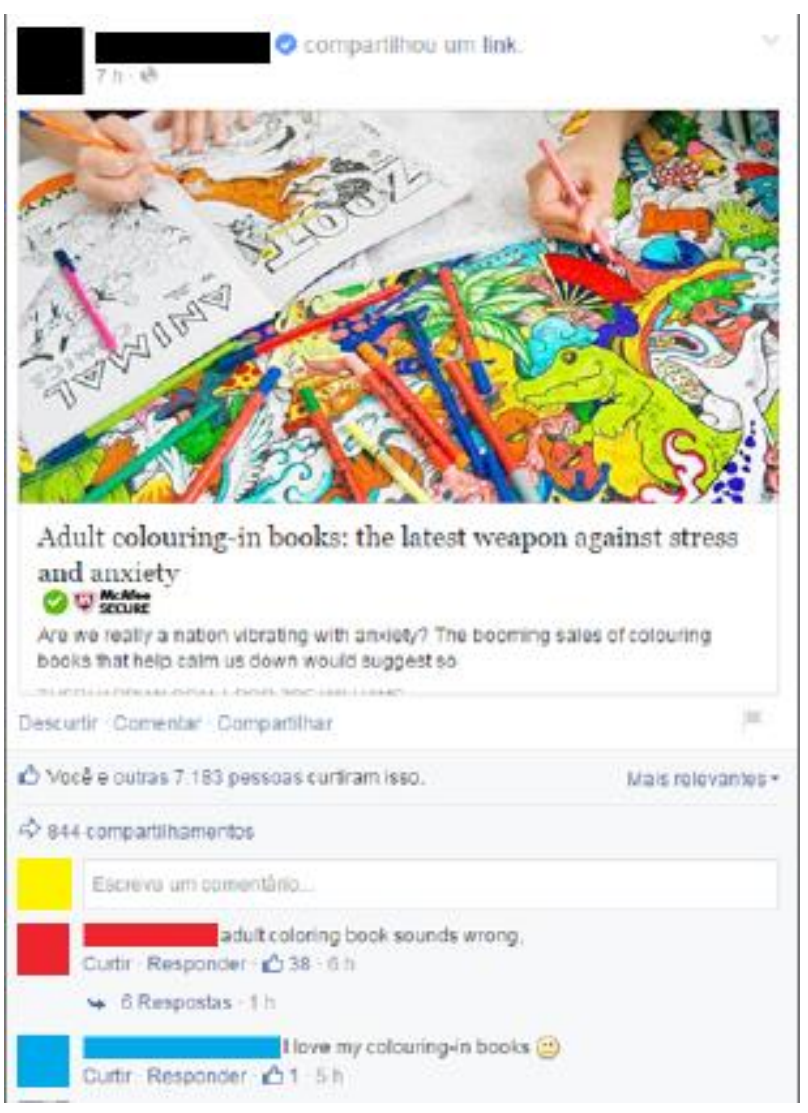

Fonte: Fanpage do Facebook do jornal The Guardian.

Outra constatação desta tendência de consumo já registrado de adultos com preferências desviantes do considerado padrão é o perfil de consumidor denominado Kidult. De acordo com o Oxford Dictionarie (tradução dos autores):

Kidult: Substantivo. 1: (Informal) Um adulto com gostos infantis. 2: (Substantivo coletivo; usado frequentemente como modificador) Um gênero de programa televisivo, filme ou jogo cuja intenção é atrair tanto crianças quanto adultos.

Estes consumidores são o principal público-alvo de segmentos como o mercado de toy $a r t^{5}$

\footnotetext{
${ }^{5}$ Também conhecidos como designer toys, são bonecos e miniaturas feitos com o intuito de exposição e decoração cujo público-alvo são adultos colecionadores.
} 
(ver figuras 13 a 15), curtas e longas de animação dirigidos para adultos (ver figuras 16 a 18), videogames $^{6}$ e um dos maiores públicos visitantes do parque temático Walt Disney World ${ }^{7}$.

Figuras 13 a 15: Os toy arts McSupersized, Luey e Squirre primam pelo fator de choque e bizarrice mostrando que o seu público alvo não é o infantil.
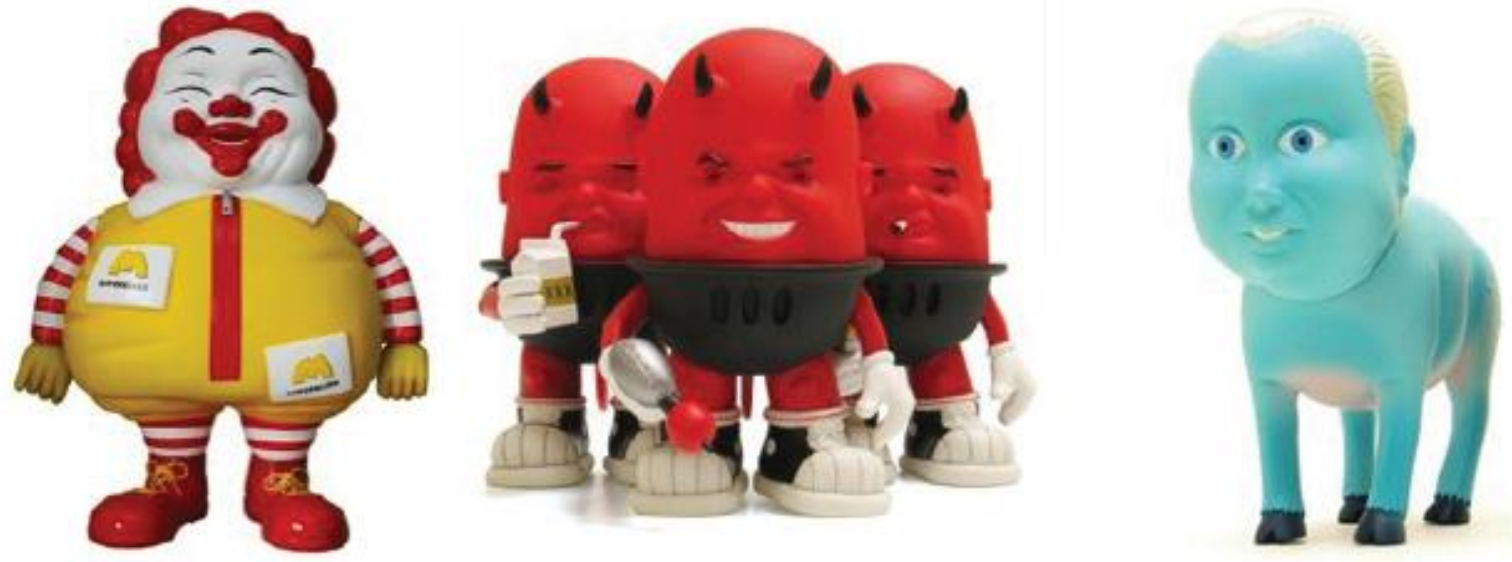

Fonte: Toy Tokyo

Figuras 16 a 18: Cena da série de animação Uma família da pesada no qual o cachorro da família morre de maneira brutal, cartaz do Festival Internacional de Animação Erótica de 2007 e cena do longa metragem Anomalisa, no qual o protagonista luta contra uma severa depressão

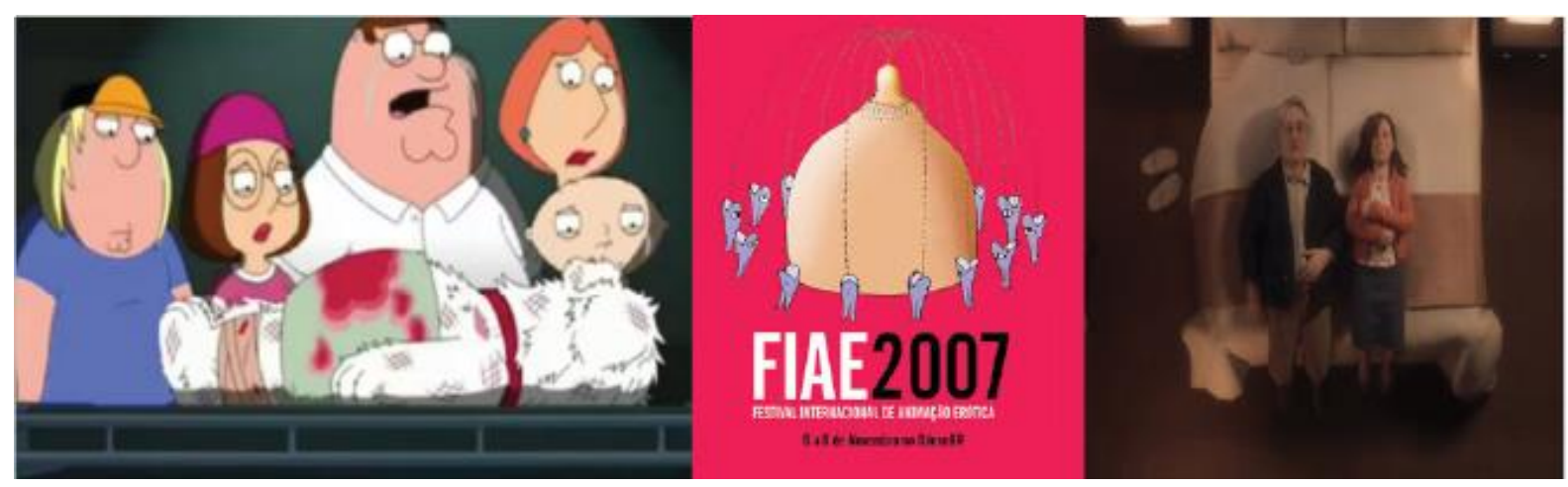

Fontes: Fox Broadcasting Company, FIAE e Paramount Pictures

O sociólogo e comentador social inglês Frank Furedi (2003), no seu artigo The children who won't grow up (em uma tradução livre, As crianças que não vão crescer), afirma que o termo kidult

\footnotetext{
${ }^{6}$ De acordo com uma pesquisa realizada em 2015 pela Entertainment Software Association (ESA) a idade média do jogador de jogos eletrônicos americano é 35 anos para os homens e 43 anos para as mulheres e, inclusive, grandes títulos têm censura para menores de 18 anos. (ENTERTAINMENT SOFTWARE ASSOCIATION. Essential facts about the computer and video game industry. Washington: 2015. Disponível em: http://www.theesa.com/wpcontent/uploads/2015/04/ESA-Essential-Facts-2015.pdf Acesso em: 24 jul 2015.

${ }^{7}$ De acordo com a revista de turismo de luxo Condé Nast Traveler, mais de 20 milhões de adultos sem crianças visitam o parque temático por ano. (LIPTON, Lauren. Visiting Walt Disney World Without Kids. Condé Nast Traveler. Nova lorque: 2013. Mai. Disponível em: <http://www.cntraveler.com/stories/2013-05-14/how-to-visit-disney-worldwithout-kids-lauren-lipton>. Acesso em: 24 jul 2015.
} 
foi criado pelos anunciantes e fabricantes de brinquedos para descrever um novo público interessado em suas ofertas. Com considerável choque e declarado pessimismo, o autor associa diretamente a predileção de adultos por temas e produtos tradicionalmente infantis (e, inclusive faz menção direta aos livros infantis e infanto-juvenis lidos por adultos) e a nostalgia com a falta de perspectiva e tomada de responsabilidades da geração de jovens e o fenômeno internacional da geração bumerangue ${ }^{8}$ (boomerang generation) , no que ele chama de peterpandemonium.

Mas importa que nós estamos perdendo gradualmente a visão do que distingue adultos de crianças? Afinal, sempre houve homens e mulheres tristes que obtém grandes prazeres de coisas infantis. Nem é o desejo de permanecer jovem peculiarmente recente. Pela história as pessoas procuraram sem descanso o segredo da juventude, e tentaram atrasar o inexorável processo de envelhecimento. A infantilização da sociedade contemporânea é dirigida por paixões bem específicas do nosso tempo. O compreensível desejo de não parecer velho foi substituído pela autoconsciente cultivação da imaturidade. Pessoas no passado queriam parecer jovens e atraentes, mas não necessariamente se comportar como crianças. A atual obsessão com coisas infantis pode parecer um detalhe trivial - mas a pervasiva nostalgia pela infância entre os jovens adultos é sintomática de uma profunda insegurança em relação ao futuro. Hesitações sobre abraçar a vida adulta refletem uma diminuta aspiração por independência, comprometimento e experimentação. (tradução dos autores) (FUREDI, 2003)

Numa posição mais mediadora, o autor de Rejuvenile: Kickball, Cartoons, Cupcakes, and the Reinvention of the American Grown-up (em tradução própria, Rejuvenil: jogos de bola, desenhos animados, cupcakes e a reinvenção do adulto americano), acredita que esta mudança social não deva ser encarada nem de maneira pejorativa nem totalmente celebrada, mas vista como tendo valor neutro. Ele acredita que adultos com gostos tradicionalmente associados a produtos e ações infantis podem ser indivíduos funcionais da sociedade, economicamente e profissionalmente estáveis e, inclusive, ser pais, como relata em sua própria experiência:

Nem me tornar pai colocou um fim nos meus gostos infantis. Na verdade, cuidar de crianças pequenas me deu a licença para tentar coisas que o livro de regras do mundo adulto certamente listava como crimes - brincar de pique-pega, pintar com manchas, comer picolé. Eu então fui forçado a reconhecer o simples mas doloroso fato de que brincar com crianças não é o mesmo que ser uma criança. Meus filhos tinham experiências simples e puras montando legos ou vendo desenhos; a minha era perfurada com kitsch (mau gosto), uma pequena dose de rebelião, e um vago senso de vergonha. Aos trinta e cinco anos, os meus interesses não deveriam ser mais sensatos - fundos de investimentos, por exemplo, ou como cuidar do gramado? O que estaria um adulto, que com exceção disso, era bem ajustado e relativamente responsável, aproveitando de PlayStation, sorvetes verdes ou Os Muppets? Eu não deveria ter "amadurecido" de tudo isto até agora? Foi desta semente de dúvida que este livro criou raízes. Falando primeiro com amigos e colegas e depois fazendo dois anos de intensa pesquisa, eu fiquei aliviado - e depois genuinamente chocado - de descobrir quantos adultos que pensavam do mesmo jeito existiam. Pessoas de todos os lugares simplesmente pararam de agir de acordo com suas idades. Eu cheguei a ideia de que a fronteira entre a vida adulta e a infância era como um posto de guarda da Guerra Fria, antes vigiado e armado, agora não guardado e poroso. (NOXON, 2006)

O professor de Comunicação Social, Joshua Meyrowitz, afirma que a televisão foi um fator chave para a diluição dessas fronteiras (1995). Segundo o autor, antes do invento e popularização dos aparelhos televisivos, era possível para os adultos controlarem e censurarem os conteúdos acessados pelas crianças, que demoram anos para serem alfabetizadas e, portanto, adquirir fluência

\footnotetext{
${ }^{8}$ Indivíduos que voltam a morar na casa de seus pais por questões financeiras e afetivas depois de adultos.
} 
suficiente na linguagem escrita para acessar conteúdos literários sem o auxílio dos mais velhos, estando assim submetidas ao seu controle.

A tv, por sua vez, traz acesso igual para todos os públicos, sem precisar de uma habilidade especial desenvolvida à priori. Homens trabalhadores e mulheres donas de casa, pobres e ricos, crianças e adultos podiam ter seus "horizontes de experiência expandidos" com o acesso a conteúdos que não eram especificamente destinados a eles. Para o autor, esse contato das mulheres com os assuntos "masculinos" de política, negócios e esportes e o dos homens com assuntos "de mulher" relacionados a cuidado pessoal, beleza e sentimentos, fez com que houvesse uma maior percepção do sexismo vigente e tornou possível o reconhecimento de interesses não ditados pelo gênero. De modo similar, a televisão tornou os "segredos do mundo adulto" expostos para crianças que se tornaram menos ingênuas e, até mesmo, menos infantis, dessa maneira os adultos, pais e professores, perderam o propósito de tentar impor sua autoridade por meios tradicionais e, portanto, a "seriedade" e "solenidade" adultas perdem uma de suas principais razões de ser.

No entanto, é necessário fazer uma ressalva. A juventude está associada a conceitos diversos como novas linguagens e comportamentos, tecnologia, saúde, beleza e potência. Atualmente, a faixa etária de 18 a 24 anos é a mais influente comercialmente, sugestionando tanto consumidores mais novos quanto mais velhos ${ }^{9}$.

Figura 19: Anúncio de creme anti-idade figurando uma modelo jovem, possivelmente mais nova que o público-alvo do produto

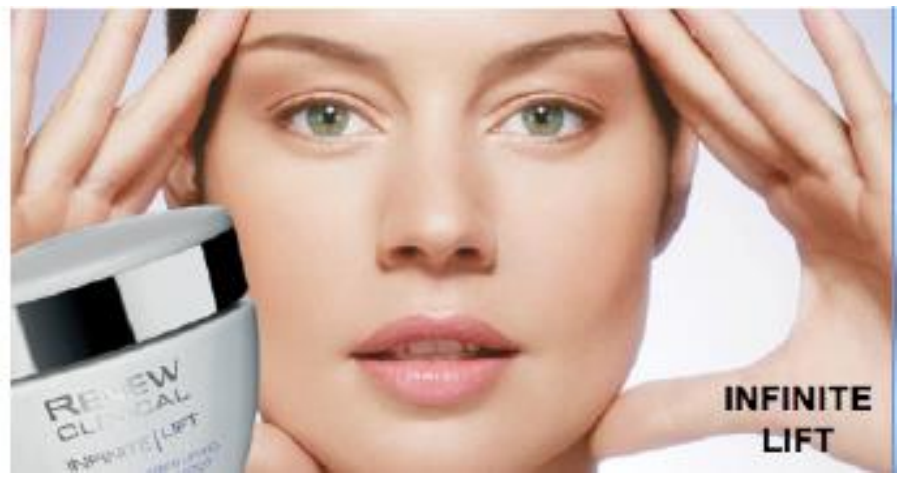

Fonte: Avon

\section{Considerações: novas maneiras de ser}

Não existe um consenso ou é acordada uma definição exata do que é ser um adulto. Em termos psicológicos, a entrada nesta fase da vida parece se dar por um conjunto de posturas individuais que abrangem a relação do sujeito consigo mesmo, com a sua família e com a tomada de responsabilidade pelos seus atos. No entanto, existe uma visão do senso comum que relaciona diretamente hábitos de consumo e fruição de bens e produtos culturais associados ao público infantil à uma suposta imaturidade e à falta de capacidade de "ser um adulto" por parte do

\footnotetext{
${ }^{9}$ Informação da agência de pesquisas em tendências de consumo BOX1824. (BOX1824. We all want to be young. Porto Alegre: 2012. Fev. Disponível em: <https://www. youtube.com/watch?v=c6DbaNdBnTM>. Acesso em: 25 jul 2015.
} 
consumidor.

A subjetividade da pessoa que é o leitor é uma essencial parte da experiência e produção de sentidos entre ele e um livro, portanto as suas expectativas, posturas e abertura a linguagens serão parcialmente moldadas por suas experiências, seus valores, sua bagagem cultural, acadêmica e, ao mesmo tempo pelo que a sociedade espera dele e lhe oferece por seu papel, pela sua formação, por sua posição social etc. Até mesmo seu entendimento do que é a Arte e seus possíveis gêneros, hierarquias e atribuição de valores é fortemente influenciado pelas pressões sociais e tradições culturais. Essas influências e constrangimentos atuam na pessoa e o leitor que ele é que, por sua vez, muito possivelmente manterá expectativas e hábitos de consumo condizentes com os dele esperados, reforçando o ciclo.

Por mais que a formação e vivência de uma pessoa em um mundo abarrotado de imagens pressuponha um certo contato e domínio da visualidade, é possível inferir que pressões e tradições tenham ecos em suas experiências com diversos produtos culturais. Dessa maneira, mesmo estando frequentemente em ambientes com grande número de imagens, os leitores são influenciados e, ao mesmo tempo, participam da validação e do reforço das pressões sociais que giram em torno do objeto livro ilustrado dirigido ao público adulto.

No entanto, simultaneamente, novas maneiras de ser - e de "ser adulto" - estão sendo formadas por pessoas cada vez mais conscientes da sua individualidade. Segundo Hall (2004) o sujeito contemporâneo tem sua identidade fragmentada. Para o autor, as "velhas" e unas identidades tradicionais: nação, religião, classe, gênero etc (e, porque não, faixa etária), que pareciam oferecer uma sólida localização de quem era o indivíduo e quais seus horizontes (de possibilidades, de ações, de gostos) sofreram profundas transformações ao longo dos séculos, trazendo uma auto-percepção mais individual do sujeito. "Dentro de nós há identidades contraditórias, empurrando em diferentes direções, de tal modo que nossas identificações estão sendo continuamente deslocadas" (2004, p. 13). As diversas facetas que definem o indivíduo são formadas por identidades muitas vezes superpostas, não excludentes, embora possam ser paradoxais entre si. Uma mesma pessoa pode ser, por exemplo, mulher, mãe, religiosa e defensora do direito ao aborto. Um adulto pode ser trabalhador, uma pessoa responsável e gostar de desenhos animados, livros ilustrados ou de usar camisas de super-heróis.

Um designer agente da cadeia de produção de livros, um profissional que tem como uma das características fundamentais de seu ofício o entendimento e valorização da linguagem visual e elementos paratextuais em vários momentos dessa produção: como capa, projeto gráfico, uso de fontes e símbolos gráficos para orientação da leitura (tais como paginação, índice e cabeçalhos etc) e, simultaneamente, uma pessoa imersa numa cultura, é influenciado e ao mesmo tempo participa da validação e do reforço das pressões sociais que giram em torno do objeto livro ilustrado. 0 profissional está inserido no mundo e é influenciado, bem como os usuários de seus projetos, por estas e diversas outras forças sociais e culturais. Por mais que o exercício de sua profissão pressuponha um certo contato e domínio da visualidade, é possível inferir que essas pressões e tradições tenham ecos em sua atuação profissional.

Uma reflexão neste sentido por parte dos profissionais, pesquisadores e professores do Design sobre o papel da área neste importante produto cultural que é o livro de ficção, bem como as possibilidades e potências de cada linguagem que nele podem ser aplicadas, pode favorecer a função social do Design de contribuir para o desenvolvimento cultural que o ser humano pode 
alcançar pela Literatura, favorecendo tanto sua educação formal quanto seu processo de humanização que a leitura de ficção propicia.

Este artigo foi fundamentado em uma pesquisa de revisão narrativa de literatura, isto é, não pretende de maneira alguma esgotar o assunto, mas, sim, apresentar algumas visões, posicionamentos e suscitar novas discussões sobre esta possível "nova identidade", nova maneira de vida adulta, que já é uma força atuante como mostra a relevante corrente de consumo para adultos com gostos fora do esperado para sua faixa etária. Os kidults inauguraram novos mercados, como o de toy art, e tendências, como a literatura de ficção para jovens adultos. As fronteiras entre infância e vida adulta, no que tange ao consumo cultural, vem se tornando cada vez mais permeáveis é esperado do designer, que participa ativamente da construção, manutenção e desconstrução de produtos e "mitos culturais" (FARBIARZ, 2008) uma (auto) reflexão que o possibilite tratar e, quem sabe, experimentar com, essas tendências e pressões.

\section{Referências}

ARNETT, Jeffrey Jensen. Young people's conceptions of the transition to adulthood. Youth and Society. New York: Sage Journals, 1997.

AUGUSTO, Sérgio. Barbies com lombadas. O Estado de São Paulo, São Paulo, 09 maio, 2015. Disponível em: < http://alias.estadao.com.br/noticias/geral,barbiescomlombadas,1684233 > , acesso em 10 de junho de 2015.

BARBOSA, Antônia Leite. Peter Pan Vive!. Casa Shopping Magazine, $58^{\circ}$ edição, ano 17, janeiro. 2016.

BOCK, Ana Mercês B., FURTADO, Odair, TEIXEIRA, Maria de Lourdes T. Psicologias: uma introdução ao estudo de psicologia. $13^{\circ}$ ed. São Paulo: Editora Saraiva, 1999. BOURDIEU, Pierre. A economia das trocas simbólicas. São Paulo: Editora Perspectiva, 1998.

ERIKSON, E. H. e Erikson, J.O ciclo da vida completo. Porto Alegre: Artes Médicas, 1998

FARBIARZ, Jackeline Lima; FARBIARZ, Alexandre; COELHO, Luiz Antônio (org.). Os lugares do design na leitura. 1a ed. Rio de Janeiro: Editora Novas Ideias, 2008.

FISCHER, Steven Roger. História da leitura. 1 ed. São Paulo: Editora UNESP, 2006.

FORTY, Adrian. Objeto de desejo - design e sociedade desde 1750. São Paulo: Cosac Naify, 2007.

FUREDI, Frank. The Children Who Won't Grow Up, Spiked, 29 de julho, 2003. Disponível em < http:// www.spiked-online.com/Articles/00000006DE8D.htm.

(http://www.frankfuredi.com/site/article/103/ > Acesso em 12 de janeiro de 2016.

HALL, Stuart. A identidade cultural na pós-modernidade. 9. ed. Rio de Janeiro: DP\&A, 2004.

LACERDA, Maíra Gonçalves; FARBIARZ, Jackeline Lima; OLIVEIRA, Izabel Maria de. Design na leitura: uma possibilidade de mediação entre o jovem e a leitura literária. Rio de Janeiro, 2013. Dissertação (Mestrado em Design) - Pontifícia Universidade Católica do Rio de Janeiro.

MEYROWITZ, Joshua. Mediating Communication: what happens?. In: DOWNING, John. MOHAMMADI, Ali. SREBERNY-MOHAMMADI, Annabelle (Org). Questioning the Media: a critical 
introduction. 2 ed. Londres: Sage Publications. 1995.

NIKOLAJEVA, Maria; SCOTT, Carole. Livro ilustrado: palavras e imagens. 1a ed. São Paulo: Cosac Naify, 2011;

NOXON, Christopher. Rejuvenile: Kickball, Cartoons, Cupcakes, and the Reinvention of the American Grown-up. Nova lorque: Crown Publishing Group, 2006

Oxford Dictionaries: Significado de "kidult" [2015] Disponível em < http://www. oxforddictionaries.com/definition/english/kidult > Acesso em 11 de novembro de 2015

RAMOS, Diogo. Por que estamos colorindo livros? [2015]. Disponível em: < http:// www.revistabula.com/4333-por-que-estamos-colorindo-livros/ >. Acesso em: 13 de julho de 2015.

RANCIÈRE, Jacques. A partilha do sensível: Estética e política. 2a ed. São Paulo: Editora34, 2009.

SADDY, Bruna Spinola; FARBIARZ, Jackeline Silva. Entendeu ou quer que eu desenhe? Um estudo sobre a percepção dos leitores sobre os livros ilustrados de ficcção em prosa dirigidos ao público adulto. Rio de Janeiro, 2016. Dissertação (Mestrado em Design) - Pontifícia Universidade Católica do Rio de Janeiro.

SADDY, Bruna; FARBIARZ, Jackeline; "Uma pesquisa de campo sobre a incidência de ilustrações nos livros dirigidos ao público adulto", p. 2681-2691 . In: Anais do 11을 Congresso Brasileiro de Pesquisa e Desenvolvimento em Design [= Blucher Design Proceedings, v. 1, n. 4]. São Paulo: Blucher, 2014.

SOCHA, Eduardo. Pequeno dicionário da teoria de Bourdieu. Revista Cult, vol. 128, setembro, 2008.

SÓCRATES. Fedro. [2012]. Disponível em: <http://filologiaunlp.files.wordpress. com/2012/01/fedro.pdf>. Acesso em: 23 set. 2014. 